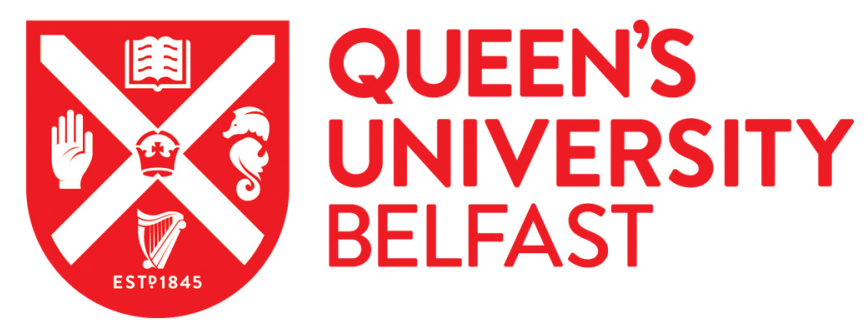

\title{
Not by associations alone: The role of contextual factors, individual differences, and propositional learning in the malleability of implicit alcohol attitudes
}

Noel, J. G., \& Petzel, Z. W. (2020). Not by associations alone: The role of contextual factors, individual differences, and propositional learning in the malleability of implicit alcohol attitudes. Addictive Behaviors, 108, [106460]. https://doi.org/10.1016/j.addbeh.2020.106460

\section{Published in:}

Addictive Behaviors

\section{Document Version:}

Peer reviewed version

Queen's University Belfast - Research Portal:

Link to publication record in Queen's University Belfast Research Portal

\author{
Publisher rights \\ Copyright 2020 Elsevier. \\ This manuscript is distributed under a Creative Commons Attribution-NonCommercial-NoDerivs License \\ (https://creativecommons.org/licenses/by-nc-nd/4.0/), which permits distribution and reproduction for non-commercial purposes, provided the \\ author and source are cited.
}

\section{General rights}

Copyright for the publications made accessible via the Queen's University Belfast Research Portal is retained by the author(s) and / or other copyright owners and it is a condition of accessing these publications that users recognise and abide by the legal requirements associated with these rights.

Take down policy

The Research Portal is Queen's institutional repository that provides access to Queen's research output. Every effort has been made to ensure that content in the Research Portal does not infringe any person's rights, or applicable UK laws. If you discover content in the Research Portal that you believe breaches copyright or violates any law, please contact openaccess@qub.ac.uk. 
Not by Associations Alone: The Role of Contextual Factors, Individual Differences, and Propositional Learning in the Malleability of Implicit Alcohol Attitudes

Jeffrey G. Noel ${ }^{1} \&$ Zachary W. Petzel ${ }^{2}$

${ }^{1}$ Univeristy of Missouri - St. Louis, ${ }^{2}$ Queen's University Belfast

\author{
Author Note \\ Jeffrey G. Noel, Missouri Institute of Mental Health, University of Missouri-St. Louis; \\ Zachary W. Petzel, School of Psychology, Queen's University Belfast. \\ Correspondence concerning this article should be addressed to Jeffrey G. Noel, Missouri \\ Institute of Mental Health, University of Missouri-St. Louis, 4633 World Parkway Circle, St. \\ Louis, MO 63134. Email: Jeff.Noel@mimh.edu
}




\begin{abstract}
Alcohol attitudes predict unique variance in drinking behavior and have been the target of manipulations and interventions to reduce high-risk alcohol use among youth and adults. However, whether these manipulations create long-lasting changes in alcohol-related attitudes and drinking behavior is unclear. The current mini-review focuses on evaluative conditioning (EC), a manipulation which pairs alcohol-related stimuli repeatedly with affectively valanced stimuli to create new semantic associations in memory; such associations underlie reflexive or impulsive behaviors like high-risk alcohol use. Across experimental studies, EC has been shown to promote negative alcohol attitudes and reduce alcohol consumption. However, recent evidence suggests the effectiveness of EC may depend on the depth of learning facilitated during the task, which may strengthen the semantic associations through propositional learning. While researchers have experimentally promoted greater depth of learning through the manipulation of contextual factors, we review evidence that alcohol-related individual differences also impact the effectiveness of alcohol EC, particularly when these factors are explicitly linked to the stimuli used during the manipulation. This review provides future directions for researchers and practitioners aiming to shape alcohol-related attitudes and behaviors. Specifically, the malleability of alcohol-related attitudes may depend on propositional learning facilitated by contextual and individual factors. Researchers and practitioners should incorporate these factors into interventions like EC aiming to reduce high-risk alcohol consumption.
\end{abstract}

Keywords: evaluative conditioning, individual differences, contextual factors, drinking behavior, alcohol 
Not by Associations Alone: The Role of Contextual and Individual Factors in the Malleability of Alcohol Attitudes

Positive attitudes among youth and adults toward high-risk alcohol use are frequently targeted for change in basic and intervention research (Reid \& Carey, 2015). These attitudes and behaviors are characterized by well-learned response habits, so that their expression may occur with little conscious deliberation or control. The purpose of this mini-review is to consider recent work from our lab focusing on evaluative conditioning (EC) as means of influencing alcohol attitudes and link our findings to those of other researchers using similar approaches. We place this work into a larger theoretical framework delineating individual differences, contextual factors, and learning processes that drive the strength and direction of EC effects. Finally, we suggest future directions for integrating EC into alcohol interventions using this framework. The core of the literature cited consists of studies we used as a basis for our research, but we sought include a wider range of relevant work searching keywords related to alcohol (e.g., "drinking behavior”), interventions (e.g., “evaluative conditioning," “cognitive bias modification”), effectiveness (e.g., "efficacy”), and variability (e.g., "individual differences," “context”) using several databases (i.e., Google Scholar, PsychINFO, PsychARTICLES). Only articles relevant to the focus of the mini-review were included (e.g., focusing on EC and related interventions facilitating change in attitudes and behavior).

\section{The Malleability of Alcohol Attitudes}

Interventions to reduce high-risk alcohol use have targeted a variety of direct versus indirect alcohol attitude measures. However, reviews and meta-analyses suggest targeting direct measures (e.g., self-report) may not have lasting effects on alcohol use (e.g., alcohol expectancies; Carey, Scott-Sheldon, Carey, \& DeMartini, 2007; Scott-Sheldon, Terry, Carey, 
Garey, \& Carey, 2012). This does not mean direct measures of alcohol attitudes are to be ignored when designing interventions; in fact, alcohol interventions in general yields mixed results (e.g., Reid \& Carey, 2015). Rather, mixed findings call for widening the range of attitudes measuredincluding the scope of assessment techniques - accounting for unique variability to develop nuanced intervention approaches.

Several indirect alcohol-related attitude measures assessing impulsive, fast valenced responses (i.e., implicit attitudes) rather than self-report attitude items predict unique variance in drinking behavior (Lindgren et al., 2016), so researchers aiming to change habitual drinking behaviors have designed manipulations targeting these measurements. A potential limitation of this approach is evidence that implicit attitudes form quickly and remain stable over time (e.g., Baron \& Banaji, 2006; Dunham, Baron \& Banaji, 2008), suggesting limited malleability. On the other hand, evidence suggests responses on indirect measures can be influenced by methods shaping underlying mental representations (Gawronski \& Bodenhausen, 2018). While novel interventions shaping these representations are effective in reducing relapse rates, meta-analyses suggest these effects are small with little to no observable effects on reduced consumption (Boffo et al., 2019; Cristea, Kok, \& Cuijpers, 2016). Thus, more research is needed clarifying which methods are most effective and establishing individual mechanisms which drive or reduce their effectiveness.

In the remainder of this mini-review, we focus on the cognitive and learning processes underlying responses to alcohol-related evaluative conditioning (EC), a technique that has demonstrated effects on both direct and indirect attitude measures (see Noel, Petzel, \& Mulderig, 2019). In this context, we discuss challenges common to any attitude change intervention and particularly relevant given the habitual nature of alcohol and drinking behavior. Although people 
attempt on their own to change, control, or suppress risky drinking behavior and attitudes, based on goals to minimize negative impacts on their health and well-being (Friese, Hofmann, \& Wiers, 2011), habitual responses can override current goals (Wood \& Neal, 2007). Therefore, manipulations targeting alcohol-related attitudes are likely moderated by contextual and individual factors driving the degree of learning needed to override well-learned responses.

\section{Associative and Propositional Learning in Evaluative Conditioning}

EC is grounded in classical conditioning, targeting emotional responses toward attitude objects by repeatedly pairing a conditioned stimulus (e.g., alcohol; CS) with an unconditioned stimulus (e.g., affectively valenced images; US). These repeated pairings create new associations between attitude objects and affective valences in memory, or rather strengthen already learned semantic relations contradicting a prevailing attitude (Hofmann, De Houwer, Perugini, Baeyens, \& Crombez, 2010). Relevant to high-risk drinking, EC is robust in reducing pro-drinking responses across a variety of direct and indirect measures when alcohol is paired with negatively valenced images (Choi \& Lee, 2015; Houben, Havermans, \& Wiers, 2010; Houben, Schoenmakers, \& Wiers, 2010; Noel et al., 2019; Petzel \& Noel, 2019; Tello et al., 2018; Zerhouni Bègue, Comiran, \& Wiers, 2018; Zerhouni et al., 2019). However, the processes underlying the effectiveness of EC is unclear. Researchers traditionally assumed these effects may be due to the formation of basic, non-elaborated associations in memory (Dijksterhuis, 2004; Olson \& Fazio, 2001; Olson \& Fazio, 2002). However, recent evidence suggests elaborated processes underlie changes in alcohol attitude measures (De Houwer, 2014; Noel et al., 2019).

A detailed theoretical account of EC is the Associative-Propositional Evaluation (APE) model (Gawronski \& Bodenhausen, 2018), which conceptualizes EC as a learning paradigm (in 
keeping with its connection to classical conditioning). More specifically, the model specifies EC effects occur via associative or propositional learning. Associative learning occurs when 2 stimuli are frequently paired together, creating basic, semantic links in memory (Gawronski \& Bodenhausen, 2006). As such, the mere co-occurrence of stimuli may be enough to influence subsequent evaluations and behavior without conscious awareness (Dijksterhuis, 2004; Olson \& Fazio, 2001; Olson \& Fazio, 2002). For example, alcohol cravings may arise from the frequent co-activation of alcohol consumption with convivial social settings. Thus, manipulations which repeatedly pair alcohol-related CS with affective US may simply create new links in memory, facilitating new reflexive responses and behaviors.

Propositional learning occurs when these associations in memory are elaborated upon, defining causal relations between mental links and determining whether these relations are true (Gawronski \& Bodenhausen, 2018). In other words, while associative learning merely facilitates the creation of links between concepts that become contiguous in memory (e.g., Alcohol-Positive affect), propositional learning includes an explanation of how these concepts may be related. Thus, after frequent co-occurrences between alcohol consumption and positive, social contexts, propositional learning may create causal representations in memory (i.e., alcohol causes sociability). Importantly, propositionally learned information is thought to be stored in semantically related nodes similar to associative learning (Gawronski \& Bodenhausen, 2018), suggesting while propositional learning may require conscious elaboration, both forms of learning may create or strengthen mental representations to alter attitudinal responses and reflexive behaviors.

Thus, while it is likely EC facilitates associative learning through the mere co-occurrence of CS-US pairings, individuals may use propositional learning to elaborate upon these CS-US 
pairings, increasing their impact. This raises the question of when propositional learning may occur to influence attitudes and behavior; if propositional learning boosts the effectiveness of EC to alter alcohol-related attitudes, this is an important question for the development of effective interventions. As we and others have found, the degree to which propositional processes occur likely depends on both contextual and individual factors.

\section{Contextual Factors}

While repeated CS-US pairing should facilitate associations, this may not be accompanied by causal links between concepts. Research has promoted propositional learning by explicitly stating the relations between CS and US during the EC task (Fiedler \& Unkelbach, 2011; Förderer \& Unkelbach, 2012; Hughes, Mattavelli, \& De Houwer, 2018). For example, inserting the word "loves" between images of a CS (e.g., man) and a positively valenced US (e.g., cute animal) promotes positive CS evaluations, whereas inserting the word "loathes" between these stimuli reverses the direction of EC effects (e.g., negative CS evaluations; Förderer \& Unkelbach, 2012). Importantly, this research shows manipulations which are thought to target mental representations may not be effective purely through the contiguity of their repeated presentation. If EC was effective solely through associative learning, then merely the presence of pairing a CS with positively valenced US should consistently elicit positive evaluations towards the CS. Instead, the direction of EC is driven not only by simultaneous presentation of CS and US but also by an individual's understanding of how they are related.

\section{Individual Differences}

Individuals seem to differ in likelihood of perceiving a propositional, causal explanation for the co-occurrence of specific US-CS pairings. For example, some participants report contingency awareness after EC (i.e., conscious of the intended effect of the manipulation), 
which seemingly boosts the effectiveness of attitude change (Hofmann et al., 2010; Zerhouni et al., 2018; Zerhouni et al., 2019). In addition to contingency awareness, individual differences which are related to experiences with or beliefs about the CS or US may inadvertently impact the effectiveness of EC through propositional learning. Such experience may strengthen EC effects, or produce effects counter to those expected based on a direct US-CS association.

For example, individuals with a greater propensity to experience disgust are more likely to be affected by EC aiming to promote aversion towards neutral objects (Olatunji, Tomarken, \& Puncochar, 2013). Thus, individual differences altering the perception of valenced US used may impact the effectiveness of EC. However, beyond perception of valenced US, certain individual factors may influence the nature of perceived propositional relations between CS-US pairings during EC. For example, manipulations aiming to reduce positive-alcohol biases may be particularly effective among heavy drinkers, but not light drinkers. In a series of studies pairing alcohol images with negatively valenced US, EC was only effective in promoting alcoholavoidance among those reporting recent binge drinking (Noel et al., 2019). In this case, the differences in the effectiveness of EC manipulations may be partly explained by an individual's previous range of experience; heavy drinkers may encounter more negative alcohol outcomes than lighter drinkers making the alcohol-negative pairings more salient, even if these drinkers typically discount negative consequences relative to alcohol-related rewards (Blume, Schmaling, \& Marlatt, 2003; Wiers, Van De Luitgaarden, Van Den Wildenberg, \& Smulders, 2005). Thus, while heavy drinkers typically exhibit strong alcohol-approach tendencies and associations compared to light drinkers (Field, Kiernan, Eastwood, \& Child, 2008), repeated pairings between alcohol and negatively valenced US may facilitate propositional or elaborative learning through 
consciously linking CS-US pairings to previously acquired information (e.g., alcohol makes me feel bad if I drink too much).

In a related study, positively valenced EC aimed at promoting alcohol-approach was more effective among drinkers who endorsed motivations to drink for the enhancement of positive emotions (Petzel \& Noel, 2019). Conversely, negatively valenced EC aimed at promoting alcohol-avoidance promoted greater alcohol-approach among drinkers reporting drinking to cope with negative emotions (Petzel \& Noel, 2019). Thus, previous experiences may have facilitated systematically different propositional learning. That is, after viewing repeated pairings of alcohol with negatively valenced US, those who drink to cope with negative emotions may form a causal relation between these stimuli using prior propositionally learned information (i.e., alcohol reduces negative affect) instead of the intended relation to be promoted by negative EC (i.e., alcohol increases negative affect). There is evidence across a number of additional studies suggesting a variety of individual predispositions towards attitude objects or valenced US may interact with the content of manipulations like EC (Brunborg, Johnsen, Mentzoni, Molde, \& Pallesen, 2011; Vogel, Hütter, \& Gebauer, 2019). Thus, individual differences may promote propositional learning of specific, even counterintuitive, explanatory links between CS-US pairings, particularly when those differences are linked to the stimuli used in these pairings.

\section{Conclusion}

Researchers aiming to develop effective interventions to change implicit alcohol attitudes and reduce alcohol consumption may want to build manipulations promoting greater propositional or elaborative learning (Gawronski \& Bodenhausen, 2018), in addition to considering contextual or individual factors influence their effectiveness. Novel experimental work has already demonstrated that paradigms such as EC may be more effective in delivering 
attitudinal change through more elaborative learning (e.g., Zerhouni et al., 2018). However, the degree that the direction of propositional learning - toward more positivity versus more negativity toward alcohol—is shaped by contextual and individual difference factors (e.g., Petzel \& Noel, 2019) is an important question for further research, as effects may be opposite those intended for some drinkers.

Despite evidence that manipulations such as EC are effective in changing acutely measured alcohol attitudes and behavior, it is fair to question the longevity of these changes. Some researchers have demonstrated changes in alcohol attitudes and drinking behavior upwards of 2 weeks after a single experimental session (Houben et al., 2010; Tello et al., 2018; Zerhouni et al, 2018). Similar approaches to changing pro-alcohol biases, such as approach-avoidance retraining, have been found to be effective for up to one year if implemented repeatedly and in conjunction with treatment (Wiers, Eberl, Rinck, Becker, \& Lindenmeyer, 2011). It is possible repetition of trials and embedding EC within other intervention approaches may similarly create longer-lasting positive change, but such work would need to examine how long-lasting any effects are as well as factors that override or lead to decay in propositional learning. It is likely that contextual and individual difference factors reviewed here, such as drinking motives, would moderate the sustainability as well as the strength of EC effects. Other contextual factors, such as social support networks that facilitate reduced versus continued heavy drinking (Litt, Kadden, Tennen, \& Kabela-Cormier, 2016), may also support or undermine new propositional learning resulting from EC.

Additional work is needed linking EC to other techniques to establish the relation between manipulations which influence responses on alcohol attitude measures and those that facilitate long-term changes in drinking behavior. Indirect measures of attitudes, due to their 
utility in predicting drinking behavior and the difficulty that people experience in controlling their expression, are linked to well-learned habitual thoughts, feelings, and behaviors. Similarly, habit can operate to drive behavior independently of conscious goals (Neal, Wood, \& Labrecque, \& Lally, 2012; Wood \& Neal, 2007). But evidence suggests that strength of habit and strength of alcohol attitudes both uniquely predict behavioral drinking outcomes (Lindgren et al., 2015). Thus, indirectly measured alcohol attitudes may accompany or perhaps even be a component of habits, yet these attitudes and habitual behavioral patterns are distinct constructs. At the very least, this means promoting a particular automatic or reflexive response through EC — such as bolstering alcohol avoidance attitudes among heavy drinkers (Noel et al., 2019) — may not impact behavioral patterns (e.g., binge drinking in social situations) unless the impulsive response we are shaping becomes strong enough to form new habits. But EC could be embedded within an intervention that strengthens newly learned responses countering established habits such as helping individuals to create specified implementation intentions toward behavior change (Sheeran et al., 2005). Shaping new habits, combined with influence techniques that bolster both associational and propositional learning of desired responses, may lead to new and effective advances in attitude and behavior change, fully realizing the promise of dual process theory and attitude measurement as tools for reducing high-risk alcohol use. 


\section{References}

Baron, A. S. \& Banaji, M. R. (2006). The development of implicit attitudes: Evidence of Race Evaluations from ages 6 and 10 and adulthood. Psychological Science, 17(1), 53-58. http://dx.doi.org/10.1111/j.1467-9280.2005.01664.x

Blume, A. W., Schmaling, K. B., \& Marlatt, A. G. (2003). Predictors of change in binge drinking over a 3-month period. Addictive Behaviors, 28(5), 1007-1012. https://doi.org/10.1016/S0306-4603(01)00287-8

Boffo, M., Zerhouni, O., Gronau, Q. F., van Beek, R. J. J., Nikolaou, K., Marsman, M., \& Wiers, R. W. (2019). Cognitive bias modification for behavior change in alcohol and smoking addiction: Bayesian meta-analysis of individual participant data. Neuropsychology Review, 29, 52-78. https://doi.org/10.1007/s11065-018-9386-84

Brunborg, G. S., Johnsen, B. H., Mentzoni, R. A., Molde, H., \& Pallesen, S. (2011). Individual differences in evaluative conditioning and reinforcement sensitivity affect bet-sizes during gambling. Personality and Individual Differences, 50(5), 729-734. https://doi.org/10.1016/j.paid.2010.12.026

Carey, K. B., Scott-Sheldon, L. A., Carey, M. P., \& DeMartini, K. S. (2007). Individual-level interventions to reduce college student drinking: A meta-analytic review. Addictive Behaviors, 32(11), 2469-2494. https://doi.org/10.1016/j.addbeh.2007.05.004

Choi, Y. J., \& Lee, J. H. (2015). Alcohol-related attitudes of heavy drinkers: Effects of arousal and valence in evaluative conditioning. Social Behavior and Personality: An International Journal, 43(2), 205-215. https://doi.org/10.2224/sbp.2015.43.2.205 
Cristea, I. A., Kok, R. N., \& Cuijpers, P. (2016). The effectiveness of cognitive bias modification interventions for substance addictions: a meta-analysis. PloS one, 11(9), e0162226. https://doi.org/10.1371/journal.pone.0162226

De Houwer, J. (2014). A propositional model of implicit evaluation. Social and Personality Psychology Compass, 8(7), 342-353. http://dx.doi.org/10.1111/spc3.12111

Dijksterhuis, A. (2004). I like myself but I don't know why: Enhancing implicit self-esteem by subliminal evaluative conditioning. Journal of Personality and Social Psychology, 86(2), 345-355. http://dx.doi.org/10.1037/0022-3514.86.2.345

Dunham, Y., Baron, A. S., \& Banaji, M. R. (2008). The development of implicit intergroup cognition. Trends in Cognitive Sciences, 12(7), 248-253. http://dx.doi.org/10.1016/j.tics.2008.04.006

Fiedler, K. \& Unkelbach, C. (2011). Evaluative conditioning depends on higher order encoding processes. Cognition and Emotion, 25(4), 639-656. http://dx.doi.org/10.1080/02699931.2010.513497

Field, M., Kiernan, A., Eastwood, B., \& Child, R. (2008). Rapid approach responses to alcohol cues in heavy drinkers. Journal of Behavior Therapy and Experimental Psychiatry, 39(3), 209-218. https://doi.org/10.1016/j.jbtep.2007.06.001

Förderer, S. \& Unkelbach, C. (2012). Hating the cute kitten or loving the aggressive pit-bull: EC effects depend on CS-US relations. Cognition and Emotion, 26(3), 534-540. http://dx.doi.org/10.1080/02699931.2011.588687

Friese, M., Hofmann, W., \& Wiers, R. W. (2011). On taming horses and strengthening riders: Recent developments in research on interventions to improve self-control in health 
behaviors. Self and Identity, 10(3), 336-351.

http://dx.doi.org/10.1080/15298868.2010.536417

Gawronski, B. \& Bodenhausen, G. V. (2006). Associative and propositional processes in evaluation: An integrative review of implicit and explicit attitude change. Psychological Bulletin, 132(5), 692-731. http://dx.doi.org/10.1037/0033-2909.132.5.692

Gawronski, B. \& Bodenhausen, G. V. (2018). Evaluative conditioning from the perspective of the associative-propositional evaluation model. Social Psychological Bulletin, 13(3), Article e28024. https://doi.org/10.5964/spb.v13i3.28024

Hofmann, W., De Houwer, J., Perugini, M., Baeyens, F., \& Crombez, G. (2010). Evaluative conditioning in humans: A meta-analysis. Psychological Bulletin, 136(3), 390-421. http://dx.doi.org/10.1037/a0018916

Houben, K., Havermans, R. C., \& Wiers, R. W. (2010). Learning to dislike alcohol: Conditioning negative implicit attitudes toward alcohol and its effect on drinking behavior. Psychopharmacology, 211(1), 79-86. https://doi.org/10.1007/s00213-010-18721

Houben, K., Schoenmakers, T. M., \& Wiers, R. W. (2010). I didn't feel like drinking but I don't know why: The effects of evaluative conditioning on alcohol-related attitudes, craving and behavior. Addictive Behaviors, 35(12), 1161-1163. https://doi.org/10.1016/j.addbeh.2010.08.012

Hughes, S., Mattavelli, S., \& De Houwer, J. (2018). Examining the impact of distance as a contextual cue in evaluative conditioning. PloS one, 13(10), e0204855. https://doi.org/10.1371/journal.pone.0204855 
Lindgren, K. P., Neighbors, C., Teachman, B. A., Baldwin, S. A., Norris, J., Kaysen, D., .. . Wiers, R. W. (2016). Implicit alcohol associations, especially drinking identity, predict drinking over time. Health Psychology, 35(8), 908-918. http://dx.doi.org/10.1037/hea0000396

Lindgren, K. P., Neighbors, C., Teachman, B. A., Gasser, M. L., Kaysen, D., Norris, J., \& Wiers, R. W. (2015). Habit doesn't make the predictions stronger: Implicit alcohol associations and habitualness predict drinking uniquely. Addictive Behaviors, 45, 139-145. doi: 10.1016/j.addbeh.2015.01.003

Litt, M. D., Kadden, R. M., Tennen, H., \& Kabela-Cormier, E. (2016). Network support II: Randomized controlled trial of network support treatment and cognitive behavioral therapy for alcohol use disorder. Drug and Alcohol Dependence, 165, 203-212. doi:10.1016/j.drugalcdep.2016.06.010

Neal, D. T., Wood, W., Labrecque, J. S., \& Lally, P. (2012). How do habits guide behavior? Perceived and actual triggers of habits in daily life. Journal of Experimental Social Psychology, 48(2), 492-498. http://dx.doi.org/10.1016/j.jesp.2011.10.011

Noel, J. G., Petzel, Z. W., \& Mulderig, T. H. (2019). Of two minds about alcohol: Specific effects of evaluative conditioning on implicit, but not explicit, alcohol cognitions among heavy versus light drinkers. Psychology of Addictive Behaviors, 33(3), 285-296. http://dx.doi.org/10.1037/adb0000449

Olatunji, B. O., Tomarken, A., \& Puncochar, B. D. (2013). Disgust propensity potentiates evaluative learning of aversion. Emotion, 13(5), 881-890. http://dx.doi.org/10.1037/a0032743 
Olson, M. A. \& Fazio, R. H. (2001). Implicit attitude formation through classical conditioning. Psychological Science, 12(5), 413-417. http://dx.doi.org/10.1111/14679280.00376

Olson, M. A. \& Fazio, R. H. (2002). Implicit acquisition and manifestation of classically conditioned attitudes. Social Cognition, 20(2), 89-104. http://dx.doi.org/10.1521/soco.20.2.89.20992

Petzel, Z. W. \& Noel, J. G. (2019). In the eye of the drinker: Drinking motives influence the effectiveness of conditioning implicit alcohol attitudes. Addictive Behaviors, 92, 24-27. https://doi.org/10.1016/j.addbeh.2018.12.010

Reid, A. E., \& Carey, K. B. (2015). Interventions to reduce college student drinking: State of the evidence for mechanisms of behavior change. Clinical Psychology Review, 40, 213-224. https://doi.org/10.1016/j.cpr.2015.06.006

Scott-Sheldon, L. A. J., Terry, D. L., Carey, K. B., Garey, L., \& Carey, M. P. (2012). Efficacy of expectancy challenge interventions to reduce college student drinking: A meta-analytic review. Psychology of Addictive Behaviors, 26(3), 393405. https://doi.org/10.1037/a0027565

Sheeran, P., Aarts, H., Custers, R., Rivis, A., Webb, T. L., \& Cooke, R. (2005). The goaldependent automaticity of drinking habits. British Journal of Social Psychology, 44(1), 47-63. http://dx.doi.org/10.1348/014466604X23446

Tello, N., Bocage-Barthélémy, Y., Dandaba, M., Jaafari, N., \& Chatard, A. (2018). Evaluative conditioning: A brief computer-delivered intervention to reduce college student drinking. Addictive behaviors, 82, 14-18. https://doi.org/10.1016/j.addbeh.2018.02.018 
Vogel, T., Hütter, M., \& Gebauer, J. E. (2019). Is evaluative conditioning moderated by Big Five personality traits? Social Psychological and Personality Science, 10(1), 94-102. https://doi.org/10.1177/1948550617740193

Wiers, R. W., Eberl, C., Rinck, M., Becker, E. S., \& Lindenmeyer, J. (2011). Retraining automatic action tendencies changes alcoholic patients' approach bias for alcohol and improves treatment outcome. Psychological Science, 22(4), 490-497. http://dx.doi.org/10.1177/0956797611400615

Wiers, R. W., Van De Luitgaarden, J., Van Den Wildenberg, E., \& Smulders, F. T. (2005). Challenging implicit and explicit alcohol-related cognitions in young heavy drinkers. Addiction, 100(6), 806-819. https://doi.org/10.1111/j.1360-0443.2005.01064.x

Wood, W. \& Neal, D. T. (2007). A new look at habits and the habit-goal interface. Psychological Review, 114(4), 843-863. http://dx.doi.org/10.1037/0033-295X.114.4.843

Zerhouni, O., Bègue, L., Comiran, F., \& Wiers, R. W. (2018). Controlled and implicit processes in evaluative conditioning on implicit and explicit attitudes toward alcohol and intentions to drink. Addictive Behaviors, 76, 335-342. https://doi.org/10.1016/j.addbeh.2017.08.026

Zerhouni, O., Houben, K., El Methni, J., Rutte, N., Werkman, E., \& Wiers, R. W. (2019). I didn't feel like drinking, but I guess why: Evaluative conditioning changes on explicit attitudes toward alcohol and healthy foods depends on contingency awareness. Learning and Motivation, 66, 1-12. https://doi.org/10.1016/j.1mot.2019.02.001 